\title{
Impact of the COVID 19: Losses and Mourning
}

\section{Eva María Esparza Meza*}

Associate Professor, Faculty of Psychology, National Autonomous University of

Mexico, Mexico

*Corresponding Author: Eva María Esparza Meza, Associate Professor, Faculty

of Psychology, National Autonomous University of Mexico, Mexico.
Received: July 18, 2020

Published: August 25, 2020

(C) All rights are reserved by Eva María

Esparza Meza.
In this work I intend or to present some reflections on what in the whole orb we are living since the pandemic produced by the SARS-CoV CoV 2 virus appeared, which has obligated us to stay confined, away from the areas of social interaction, in a constant distress that has led us to modify the patterns of life used..

Since we were born, the human being is subject to the effects of living all kinds of losses: loving, family, social, labor, economic, etc. In fact, birth is the first great loss that we have to face, because at birth the comfort in which it was inside the mother's womb is lost, where nothing was missing.

At birth we humans are in a situation of absolute deviation, to survive we depend on the physical and psychic care that is provided to us. The state of helplessness resulting from the immaturity with which we are born, is compensated by the devoted care of the mother, who, with the support of her partner, family and society in general, lends the baby a kind of external nesting that subjudges this first catastrophe called birth.

This initial dependence will still last a long time and independence while one of our life tasks is to achieve the emotional and economic independence of the parents that will grant us the status of citizens, autonomy will never be absolute, but rather relative; our life will always be linked to that of others, and indeed one of the most important aspects of what we call living, is the establishment of lasting affective bonds with others, we are assiduous to the affection that the significant persons lavish us and we cannot do without it. When we are denied, when we lose it we suffer too much.

As we can realize, since we are small, life holds us many losses and resignations, but this does not necessarily have negative impli- cations, on the contrary, these experiences are giving us the ability to face and transform its effects, with which we gradually strengthen, so that we learn to deal with the feelings produced by these situations of breakout, we are doing, we are becoming, as colloquially of hard leather. In this sense, even in the best of environments, disappointment, suffering and frustration are inevitable, we are all exposed to them, and we have to learn to recognize, feel and face them, rather than repress, deny or avoid them.

This ability to tolerate suffering, to face the pain of losses depends on the conditions that surround our lives, so that some people develop greater strength, while others will be more vulnerable and in circumstances of misfortune can easily fall into unused despair and anguish.

So far, I have mentioned about the circumstances that help us conform, to build ourselves as subjects; however, there are situations of loss that due to their magnitude or significance often produce a harmful effect that sometimes exceeds our ability to tolerate and face its repercussions, such as the death of loved ones: parents, siblings, children, couple or when diseases occur that prevent us from continuing with a normal life. Thus, for example, the death or abandonment of one of the parents at an early age, usually produces devastating aftermath in life; and what to say about the death or illness of a child, all of these are events that can be overcome, but that leave wounds that are often impossible to close, and that from time to time they will reawaken the pain that was originally felt.

The emotional state that arises after a loss is known as grief. And the duel is the affective response to loss, we lose our appetite, we lose sleep, we lose interest in what we liked before, the level of activity used to it is decreased, we do not want to see others and we lock ourselves in a deep sadness. This is an absolutely expected 
state when something that we consider valuable is lost, whether it is a person, a loving bond, a job, or even a material possession; it represents the tendency to hold on to others, it is the remnant of our child dependence and means the intensity of affection that is placed on what was lost, something of us, of our essence also leaves, and it will take time to regain interest, desire.

The duel will go through different stages from the denial of what happened to the acceptance of the loss, will take a moment or recover, but will be achieved. Even with all the pain that grief can become, it is a process that must be lived, when for some reason there is an absence of grief or rather the phase of denial or avoidance is prolonged, the result is an clogged duel that instead of being assimilated, ends up being eternized and then its pernicious effects will begin to manifest through symptoms such as addictions, impulsivity, problems of food, sleep, depression, the situation will be so complex that the person will not be able to recognize the origin or reason for his suffering.

On the other hand, when the person has developed a fragile, vulnerable psychic structure, without sufficient strength until the most insignificant losses will generate an intense emotional response of mourning that can last indefinitely and become a pathological duel.

Adversity involving death or the aforementioned losses are events that human being known and generally fear. Fear of death is one of the most intense anxieties, because in general no one wants to die; however, when we face the death of a loved one, even in the most painful cases, we have the recourse of farewell that takes place during a ceremonial or funeral that allows us to play off and socialize with others the pain, the sadness of the loss, because we know that we count on others to hear our sorrows and rinse our tears.

On the other hand, there are also other catastrophic events that we can raise and that, by the frequency with which they occur, the human being has tried to control, develops prevention measures to counteract its devastating consequences, such as in the case of hurricanes, floods, fires and even earthquakes.. To protect us from the harmful effects of these calamities, which can cause great losses, usually resortors to the comfort and protection of others; let us remember that since we are born we are social beings and we promote sociability, being close to others becomes vital, we like them to care about our well-being and at the same time seek the well-being of others, this affinity and social affability has been ex- tremely important to succeed when we experience both personal losses and when we suffer the breakdowns of the great cataclysms.

In these circumstances what threatens our everyday life is well identified, it is something tangible, we can be very afraid, but we know what we face, even in the case of wars, the enemy has a name so to speak. However, there are certain less frequent and therefore unknown events, such is the case of what we are currently experiencing: the pandemic produced by the SARS-VOC 2 virus, and it is not that it is the first bread of me that human beings face, the terrible black plague, smallpox and cholera has already passed, we know that a century ago the so-called Spanish fever occurred, all these pandemics are distant, strange and unthinkable events and perhaps we come to fantasize that given the current technological and scientific advances, they would not happen again or we would have enough resources to combat them, all these which, as we are seeing did not happen, the pandemic recalls again and strikes the fragility of humanity, lowers us from the pedestal of omnipotence.

Paradoxically the COVID 19 pandemic has brought with it both positive and negative things, it is undeniable that he caught us unprepared, in a state of unprepared both in the sense of health strategies as well as socially and psychologically speaking, he came to break with the everyday, the foreseeable, what was known to us, introduced a permanent state of uncertainty, not knowing if there is a cure and tomorrow we will be healthy or dead, the future is now tinged with perplexity. Thus, the virus is an evil entity and danger so that places us in a context of life and death, represents an underfeeds threat that arouses not only bewilderment, but also dismastment, revival of a feeling of helplessness that was already lived when we were born, but which unlike that, where homelessness was mitigated by the protection of the mother, this time the protection is sought in the state, although it must also be said in false beliefs and magical thought; we realize as for a sector of the population, since the virus has the quality of being intangible, its invisibility leads to the emergence of rumors: "there is no, Soneraglion Shion, Pro invention to confuse, was created to produce" these expressions are not only the product of ignorance and misinformation, they can also be the manifestation of the fear of the imperceptible, the feeling of helplessness, before which it is resorted to the protection of omnipotence, of invulnerability: "nothing is going to happen to me", "I am not afraid because that does not exist". And it doesn't exist until you touch them, until you penetrate it and experience its effects on your own flesh. 
The losses arising from the pandemic have been immense, many aspects of life have been disrupted: economics, schooling, family and social life, sexuality; we have lost our security, fear makes theirs able to paralyze and lead to the pani people who have previously been in a state of psychological vulnerability. Within the negative it is necessary to include the loss or even the latent threat of losing health and life; death, beyond the numbers is there, prowling everywhere and when people have unfortunately faced the death of a loved one, the experience of normal mourning has been hindered by circumstances, the inability to care for their sick, de of physical farewell, of having the funeral ceremonies to which we were accustomed, have made the emotional work of grief more difficult; the reactions we have seen vary, some are added in a dry sadness by the lack of the company of others, because the wakes and burials serve to share pain, to accompany the sorrow; there have also been incomprehensible reactions of anger and aggression, but which are explained because they are the manifestations of magical-superstitious beliefs: because where there is no body there is no death, because the virus does not exist, it is only an invention, because they feel deceived, and why they do not accept their responsibility by having defied the invisible threat, all the anger caused by confusion and bewilderment, moves to those in which the magical power of saving is deposited.

The only certainty we have before the pandemic is that all of us: children, young people and adults, are crossed by this situation generating anguish. Young children have lost their spaces of coexistence, academic and social learning, they were hardly learning certain rules when suddenly everything changed. Adolescents and young people have found the need to give up their daily social environment, which clearly represents a significant loss, because during adolescence the social aspect is fundamental to the achievement of identity and autonomy; even though we consider today's young people as the native generation in technology, what we've seen in research targeting this population, is that they also prefer personal contact, the reference framework provided by their social group has been altered because obviously a screen in between is something that serves to maintain social contact with the outside, but that is not enough; on the other hand, the technology has been used more as a means of entertainment than learning, and so we find that online teaching has not been as simple as might be thought and will require time to be coupled.

Adults are also experiencing significant losses, not only are they the most exposed population, but they are also the ones who have most resented economic effects, because most of them fall responsibilities and this in turn impacts within the family dynamic that can be lived with a lot of distress and become a stressful atmosphere and lead to expressions of violence.

The pandemic has broken into everyone's life generating fear, bewilderment and anguish, re-action normal to a threat, their threatening in the case of the pandemic is the deadly tendency, which frightens us with the destruction of the known. This anguish is like an intense noise that suddenly disturbs stillness and continuity; when we have abundant and varied internal resources to control it we can restore balance more easily, this ability to handle distress depends on various factors such as age, from the emotional state foreseen to the catastrophic event, of social networks and supporting relatives available to support the individual; when strategies to deal with distress fail, it overflows and it overflows floods us, becomes a catastrophic, unthinkable anguish, of an endless fall that can produce an emotional disorganization emotional with physical symptoms such as insomnia, nomalogies, dizziness, sweating, palpitations; which in more severe cases can manifest itself with symptoms of depersonalization, hallucinations, delusions, paranoia, etc.

Of course we do not all experience this situation of the same way, for some it means a moment of opportunity, of happiness, so some children and young people feel happy to spend more time with their parents, because they now pay them more attention and care. Others have taken the opportunity to learn and do what they couldn't before because of the turmoil of lifestyles. Some have gained economic benefits. Others will live it as an emotional whirlwind and suffer greatly from loneliness, affective and economic deficiencies, family discrepancies.

Each person has a limit to tolerate the blows that this calamity has caused us, without breaking, without being unstructured, without the anguish invading it, but this as I mentioned depends on the internal strength and, paradoxically, of social support even if, virtual. There is still time for us to say that we have come out well rid of this, we are required to have a lot of strength and clarity, accept helplessness and learn to wait, it takes great patience to overcome physical and psychological exhaustion, all are necessary elements to win the battle to this invisible but present threat.

The experience of the pandemic will leave in our lives deep emotional scars, but it is important that vitality is not exhausted, 
in this sense social support is a fundamental part to avoid sinking, hopelessness, depression. To recover the desire to live, to love, there are various possibilities, an exit is to throw itself into an unbridled situation, trying to recover what is lost through the inexhaustible search for absolute satisfaction, which can lead to greater destructiveness and to find that which is avoided to be death. The other possibility is to seek more creative ways of existence, by understanding the needs of others, of the Andes cattle, of the exploitation of the world and of what it offers us and above all of the encounter with the depths of ourselves.

We must conjure fear and an effective way to do it is humor, I have seen many very ingenious memes about the coronavirus, laughing allows us to distance ourselves from fear and subtract malignancy from catastrophe. It is also time to repair, to reconcile with life or to those we love and pride has prevented them from telling them and we have turned them away.

This invisible enemy has not placed in a situation where what is at risk is not only health, but life itself; it is imperative to set aside the banal, because the priority is to survive, to achieve it we must be strong, patient and empathetic, take care of one another, overcome individualism and change it by solidarity, otherwise, all of us will lose, humanity will have lost.

\section{Assets from publication with us}

- Prompt Acknowledgement after receiving the article

- Thorough Double blinded peer review

- Rapid Publication

- Issue of Publication Certificate

- High visibility of your Published work

Website: www.actascientific.com/

Submit Article: www.actascientific.com/submission.php

Email us: editor@actascientific.com

Contact us: +919182824667 